Article

\title{
A novel iron-chelating polyimide network as a visible-light-driven catalyst for photoinduced radical polymerization
}

\author{
Gang Ding a,b, Qin Wang a, Fei Liu a, Yi Dan a,\#, Long Jiang a,* \\ a State Key Laboratory of Polymer Materials Engineering of China (Sichuan University), Polymer Research Institute of Sichuan University, Chengdu \\ 610065, Sichuan, China \\ b School of Materials Science and Engineering, Southwest University of Science and Technology, Mianyang 621000, Sichuan, China
}

\section{A R T I C L E I N F}

\section{Article history:}

Received 29 February 2020

Accepted 12 April 2020

Published 5 January 2021

\section{Keywords:}

Visible-light

Photopolymerization

Polyimide photocatalyst

Iron chelating

\begin{abstract}
A B S T R A C T
With the aim of developing a low-cost and efficient visible-light-driven photocatalyst for radical polymerization, iron-chelating polyimide networks (Fe@MPI) was fabricated by firstly synthesizing photoactive melamine-containing polyimide (MPI) networks and then incorporating Fe(III) cations into the polymer networks. Fe@MPI exhibits a wide absorption spectrum ranging from 220 to 1250 $\mathrm{nm}$ and 3.5 times higher photocurrent intensity as compared with the pristine MPI. Based on its excellent photo-electric properties, Fe@MPI was employed as a recyclable heterogeneous catalyst, providing sufficient activity for the visible-light driven radical polymerization to synthesize poly(methyl methacrylate) with molecular weight up to $31.3 \times 10^{4} \mathrm{~g} / \mathrm{mol}$. Taking advantage of the heterogeneous nature of the catalyst, Fe@MPI could be facilely regenerated from the polymerization solution by filtration without an obvious loss of its activity. This research provides a novel recyclable catalyst for visible-light driven radical polymerization.
\end{abstract}

(C) 2021, Dalian Institute of Chemical Physics, Chinese Academy of Sciences. Published by Elsevier B.V. All rights reserved.

\section{Introduction}

Annually, million tons of radical polymers including polyacrylates, polystyrene, and polyvinyl esters were produced through thermally initiated polymerization, and these manufacturing processes consumed tremendous amount of fossil fuel-based energy, which may further deteriorate the growing issues of energy shortage and the environmental crisis [1]. In comparison with fuel energy, solar energy is clearly one of the most promising and abundant sustainable energy resources. Thus, an ideal way to limit the reliance on non-sustainable fuel energy is to develop photo-induced polymerization techniques that can directly convert monomers into polymers using sun- light, especially visible-light, by mimicking natural photosynthesis [2,3]. However, ultraviolet light has always been the protagonist in organic photochemical research in the past decades due to the efficient absorption of UV irradiation by carbon-based compounds [4,5]. But practical applications of this technology for polymerization have been significantly limited by the disadvantages of UV including poor penetration through organic substances, uncontrolled material damage caused by photolysis, and the low proportion of UV in the solar spectrum ( $\sim 5 \%-8 \%$ depending on the season) [6,7]. Thus, visible-light driven photocatalysts for radical polymerization are of growing interest from both the industrial and academic points of view.

Recently, visible-light-driven homogeneous catalysts for

\footnotetext{
* Corresponding author. Tel: +86-28-85405410; Fax: +86-28-85402465; E-mail: jianglong@scu.edu.cn

\# Corresponding author. Tel: +86-28-85405410; Fax: +86-28-85402465; E-mail: danyi@scu.edu.cn

This work was supported by the National Natural Science Foundations of China (51573109), the State Key Laboratory of Polymer Materials Engineering (sklpme 2016-3-02 and 2019-2-08), and the Fundamental Research Funds for the Central Universities.

DOI: 10.1016/S1872-2067(20)63610-5 | http://www.sciencedirect.com/science/journal/18722067 | Chin. J. Catal., Vol. 42, No. 1, January 2021
} 
photosynthesis have been successfully developed, but most of them are based on precious metal chromophores such as lanthanum, rhodium and iridium complex [8-10], suffering from high cost, limited availability, and sensitivity to catalyst poisoning, as well as time and energy consuming separation process [11-13]. In comparison with precious metal based photocatalysts, conjugated polymer-based organic photocatalysts are good candidates for photoinduced reactions because of the broad absorption in the range of visible light region, cost-efficient, versatile building units with excellent tunability in relation to chemical, textural, and electronic structures [14-16]. The history of polymeric photocatalyst can be traced back to linear poly(p-phenylene) (PPP), reported by Yanagida et al. [17] in 1985. Unfortunately, PPP conducted photocatalytic reactions with insufficient activity under both visible-light and UV irradiation, probably due to the fast recombination of photo-generated charge carriers. Moreover, another fatal drawback of photocatalysts based on linear conjugated polymers is their poor chemical and photo-stability. With the aim to overcome these drawbacks, photocatalysts based on highly crosslinked conjugated microporous polymers (CMPs) starting from benzene [18], pyrene [19], melamine [20,21] and thioether [22] building blocks were well developed. Compared with linear conjugated polymers, CMPs possesses several remarkable advantages including the heterogeneous nature that makes them easy to separate, large specific surface area and molecular-level control of chemical structure and photophysical properties including bandgap and band edge. Thus, a series of conjugated microporous polymer network have been successfully conducted for photocatalytic applications [23-26]. Among these CMPs, polyimide networks which were firstly reported by Wang et al. $[27,28]$ stands out with brilliant future due to its long-term stability against photo-degradation and chemical corrosion and scalable synthesis strategy, which are of pivotal importance to photocatalyst. However, polyimide networks, like other CMPs, also suffer from insufficient photocatalytic activity [29-31]. In order to facilitate the separation of photo-generated charge carriers, a polyimide network containing triphenylamine electron donor units were previously reported by our group, and acceptable photocatalytic performance was achieved when photodegradation of organic pollutants in aqueous solution was conducted [32]. Although significant progress has been achieved in developing CMPs-based photocatalysts [33-38], their practical application for visible-light driven radical polymerization in organic solution is proving to be more challenging than those previously reported applications like photocatalytic decontamination and water splitting, basically because of the insufficient activity of CMPs to generate reactive carbon centered radicals in an organic environment [39].

Herein, we provide an easily available heterogeneous photocatalyst for visible light driven radical polymerization. By employing melamine as electron-donating units and 1,4,5,8-naphthalenetetracarboxylic dianhydride as electron-accepting units, melamine polyimide network (MPI) containing alternating D-A structure has been constructed via polycondensation, following our previously reported research
[32]. To further increase its photocatalytic activity, Fe(III) cations has been incorporated into MPI to form a Fe(III) doping polyimide network (Fe@MPI), which enables the radical polymerization of methyl methacrylate under visible-light irradiation. Meanwhile, Fe@MPI can be easily separated from the polymerization solution due to its heterogeneous nature, and reused without an obvious loss of its activity.

\section{Experimental}

\subsection{Materials}

Methyl methacrylate (MMA, Chengdu Kelong Chemcial Reagent, AR, 98\%) was distilled under reduced pressure. 1,4-dioxane (Chengdu Kelong Chemcial Reagent, AR, 99.5\%), iron chloride $\mathrm{FeCl}_{3}$, Chengdu Kelong Chemcial Reagent, $\mathrm{AR}$, 98\%), ethanol (EtOH, Chengdu Kelong Chemcial Reagent, AR, 99.7\%), triethylamine (Et3 $\mathrm{N}$, Chengdu Kelong Chemcial Reagent, AR, 99\%), methanol (MeOH, Chengdu Kelong Chemcial Reagent, 99.5\%), hydroquinone (Chengdu Kelong Chemcial Reagent, AR, 99\%), 1,4,5,8-naphthalene tetracarboxylic dianhydride (NTCDA, Broadway Technology Co., Ltd, AR, 97.5\%) and melamine (MA, Broadway Technology Co., Ltd, AR, 99\%) were used as received. The light source used for all experiments was ExdI IBT4Gb explosion-proof light purchased from Zhongshan Balin Lighting Co., Ltd.

\subsection{Synthesis of Fe(III) doping polyimide network (Fe@MPI)}

Firstly, melamine polyimide network (MPI) was synthesized by the polycondensation of 1,4,5,8-naphthalene tetracarboxylic dianhydride (NTCDA) with melamine. Typically, melamine (MA, $0.1262 \mathrm{~g}$ ) was dissolved in N-methylpyrrolidone (NMP, 10 $\mathrm{mL}$ ) at $25{ }^{\circ} \mathrm{C}$ under $\mathrm{Ar}$ protection in a $50 \mathrm{~mL}$ three-neck round-bottomed flask equipped with magnetic stirring bar. The $\mathrm{n}$ a solution of 1,4,5,8-naphthalene tetracarboxylic dianhydride (NTCDA) in NMP (10 mL, $0.15 \mathrm{mM}$ ) was slowly dropped into the flask approximately within $4 \mathrm{~h}$. The primary reaction was carried out at $25{ }^{\circ} \mathrm{C}$ for $24 \mathrm{~h}$, then continued to react at $40{ }^{\circ} \mathrm{C}$ for $24 \mathrm{~h}$ to obtain polyamide acid. After the reaction finished, the mixture solution was poured into ethanol for precipitation, then filtered and washed under reduced pressure to obtain a light yellow powder. Finally, the powder was put into muffle furnace and calcined for $1 \mathrm{~h}$ at each temperature $(100,150$, 200,250 and 300 , and the heating rate is $2.5^{\circ} \mathrm{C} / \mathrm{min}$ ) for thermal amination to obtain an orange-yellow melamine polyimide network (MPI).

Then, Fe(III) was incorporated into MPI to form Fe@MPI through chelation reaction. Typically, MPI powder (50 mg) was suspended in deionized water $(50 \mathrm{~mL})$ with the assistant of 30 min of ultrasonic irradiation. Then, $\mathrm{FeCl}_{3}$ aqueous solution (50 $\mathrm{mL}, 0.1 \mathrm{M}$ ) was introduced into the suspension under ultrasonic irradiation at room temperature, and the chelation reaction was conducted under magnetic stirring in a water bath maintained at $60{ }^{\circ} \mathrm{C}$ for $6 \mathrm{~h}$. Orange-yellow Fe@MPI precipitates were separated from the reaction mixture by filtration, dialyzed against deionized water to eliminate any free Fe(III) cat- 
ions, lyophilized and then stored in dark for further use in the photocatalytic tests.

\subsection{Photopolymerization of MMA with Fe@MPI}

Photopolymerization of MMA with Fe@MPI was typically conducted as follows: In a quartz reactor equipped with a water-cooling system, a mixture of MMA (0.1058 mol), dioxane (5 $\mathrm{mL}$ ), Fe@MPI (343.5 mg, $1.06 \mathrm{mmol}$ ), and triethylamine (175 $\mu \mathrm{L}, 1.06 \mathrm{mmol}$ ) were placed. The vial was bubbled with argon for at least $30 \mathrm{~min}$ in dark to remove oxygen. After the degassing treatment, the quartz reactor was tightly closed and irradiated under Xenon lamp for $6 \mathrm{~h}$ with magnetic stirring at $30^{\circ} \mathrm{C}$ to carry out the photopolymerization. A $100 \mathrm{~W}$ Xenon lamp with a cut-off filter ( $>420 \mathrm{~nm}$ ) was used to provide visible-light irradiance level at about $12.2 \mathrm{~mW} / \mathrm{cm}^{2}$. After polymerization, Fe@MPI was regenerated from the polymerization mixture by filtration, washed with THF and DI-water, and then dried in dark at room temperature under vacuum to achieve constant weight. Meanwhile, PMMA was isolated by precipitation in methanol, and the precipitated polymer was filtrated, washed with methanol and then dried under vacuum at $40{ }^{\circ} \mathrm{C}$ until a constant weight was achieved.

The recovered Fe@MPI was re-served as the photocatalyst to induce the visible-light driven photopolymerization of MMA under the identical conditions to evaluated the recyclability of Fe@MPI.

\subsection{Characterization}

Fourier transform infrared (FT-IR) spectra of MPI and Fe@MPI powders were recorded on Nicolet iS10 FTIR spectrometer (Thermo Fisher Scientific Inc., USA), where samples were dispersed in KBr. Powder X-ray diffraction (XRD) measurements were carried out in air with a DX-2500 spectrometer (Dandong, China). Scanning electron microscopy (SEM) and energy dispersive X-Ray spectroscopy (EDX) were conducted on Phenom G2 ProX scanning electron microscope (Netherland), where the surface of the sample was pretreated by gold spray. Transmission electron microscopy (TEM) was conducted on LIBRA 120 transmission electron microscope (Carl Zeiss, Germany). The Brunauer-Emmett-Teller (BET) specific surface area and porosity were measured on a Quantachrome Instruments 1900 surface area and porosimetry analyzer (Quantachrome Instrument Corporation, USA) based on $\mathrm{N}_{2}$ adsorption at $77 \mathrm{~K}$. X-ray photoelectron spectra (XPS) were undertaken on Escalab 250Xi spectroscope (Thermo Scientific). UV-visible diffused reflection spectra of solid samples were recorded on a UV-2600 spectrophotometer (Shimadzu, Japan) at a scanning speed of $400 \mathrm{~nm} / \mathrm{min}$ and recorded in the range of 200 to $1400 \mathrm{~nm}$. The Inductively Coupled Plasma Optical Emission Spectroscopy (ICP-OES) measurement was performed with a sequential ICP spectrometer (Agilent, China). Electron paramagnetic resonance (EPR) was carried out on a Bruker EPR EMX Plus (Bruker, USA) with a frequency of approximately $9.8 \mathrm{GHz}$ using a standard microwave power of 0.1 $\mathrm{mW}$. The photocurrent analysis was carried out on a CHI 760E electrochemical system under visible light irradiation. A three electrode quartz cell was used for the measurement with $\mathrm{Pt}$ as the counter electrode, $\mathrm{Ag} / \mathrm{AgCl}$ or saturated calomel electrode (SCE) as the reference electrode, the thin film of MPI or Fe@MPI on indium-tin-oxide (ITO) glass as the working electrode, and $0.1 \mathrm{~mol} / \mathrm{L}$ of $\mathrm{Na}_{2} \mathrm{SO}_{4}$ aqueous solution as the electrolyte, respectively. The conversion rate of polymerization was calculated by gravimetric method, and the molecular weight and molecular weight distribution of the polymer were determined by GPC20AD gel permeation chromatograph (Shimadzu, Japan) with THF as mobile phase at a flow rate of 1 $\mathrm{mL} / \mathrm{min}$; the relative molecular weight was calibrated against polystyrene standards.

\section{Results and discussion}

\subsection{Structure and morphology}

Herein, we report a novel iron-doping polyimide network (Fe@MPI) and its use as photocatalyst for visible-light driven photopolymerization. Initially, the alternating D-A polyimide network was fabricated by the polycondensation of melamine (MA, electron-donating unit) and NTCDA (electron-accepting unit) in NMP via thermal imidization, and then Fe(III) cations were incorporated into MPI to form the heterogeneous photocatalyst Fe@MPI, as shown in Fig. 1(a). The FTIR spectrum of MPI was overlaid with spectra of melamine and NTCDA comonomers to monitor the imidization procedure (Fig. 1(b)). From the spectrum of NTCDA, peaks at 1780 and $1732 \mathrm{~cm}^{-1}$ which belong to the anhydride $\mathrm{C}=0$ stretching vibration can be clearly observed. But in MPI, the peaks of $\mathrm{C}=0$ stretching vibration largely shifted to 1719 and $1681 \mathrm{~cm}^{-1}$, respectively, suggesting the formation of imine linkage [40]. Additionally, the characteristic peak of triazine ring aromatic $\mathrm{C}=\mathrm{N}$ stretching vibration at $1520 \mathrm{~cm}^{-1}$ [41] belonging to melamine cores was also observed in the spectra of MPI, confirming the polycondensation between melamine and NTCDA. Meanwhile, it's worth to note the residue of $\mathrm{C}=0$ at 1790 and $1754 \mathrm{~cm}^{-1}$ in MPI, probably due to the imperfect polycondensation between NTCDA and melamine. FT-IR spectroscopy was also utilized to monitor the doping of Fe(III) cations into MPI. Fig. 1(c) presented the overlaid FTIR spectra of Fe@MPI and MPI, and a new broad peak at around $610-690 \mathrm{~cm}^{-1}$, designated as the vibration peak of $\mathrm{Fe}-\mathrm{N}$ or $\mathrm{Fe}-\mathrm{O}$ [42-44], appears in the spectrum of Fe@MPI, illuminating the successful coordination of Fe with MPI. Meanwhile, the stretching vibration of triazine ring aromatic $\mathrm{C}=\mathrm{N}$ at $1520 \mathrm{~cm}^{-1}$ as well as the stretching vibration of $\mathrm{C}-\mathrm{N}$ at $1205 \mathrm{~cm}^{-1}$ have a slightly redshift of about $3 \mathrm{~cm}^{-1}$, confirming the coordination of Fe with triazine ring. Although no significant change in the imine $\mathrm{C}=\mathrm{O}$ stretching vibration (1719 and $1681 \mathrm{~cm}^{-1}$ ) can be observed, the residual anhydride $\mathrm{C}=0$ stretching vibration peaks at 1790 and $1754 \mathrm{~cm}^{-1}$ was markedly reduced in intensity (Fig. 1(c)), suggesting a ring opening of the residual anhydride moiety and its subsequent coordination with Fe(III) cations.

The success incorporation of Fe cations into MPI network is confirmed by XRD measurements (Fig. 2). From the XRD pat- 
(a)

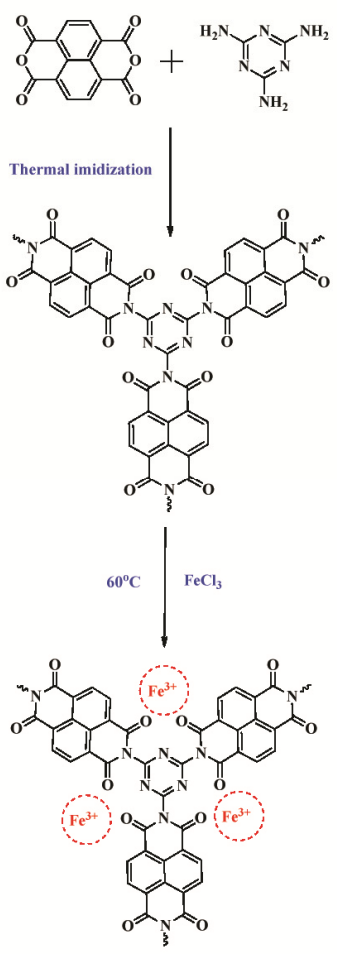

(b)
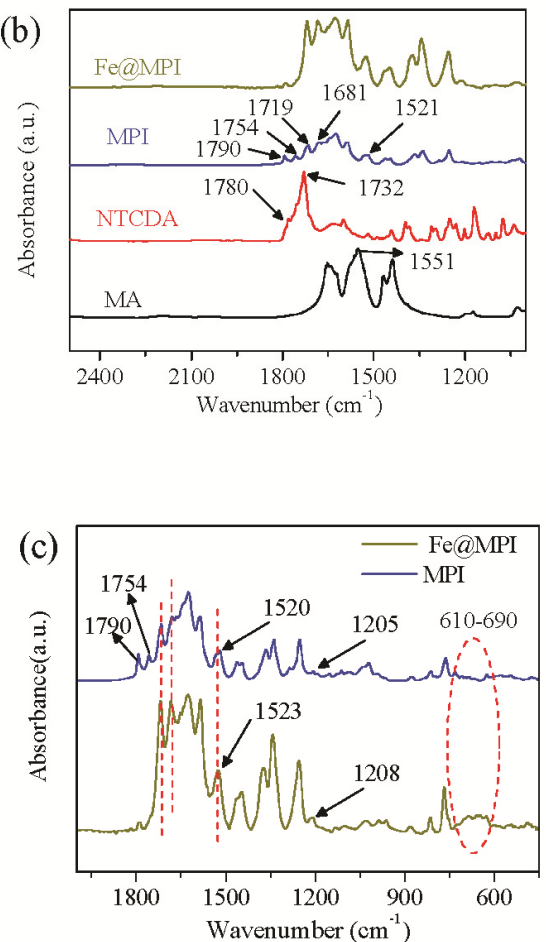

Fig. 1. (a) Schematic diagram of the synthesis of MPI and Fe@MPI; (b) full FT-IR spectra of NTCDA, melamine, MPI and Fe@MPI; (c) the zoom-in FT-IR spectra of MPI and Fe@MPI.

terns, we can clearly observe the existence of long-range crystalline order in the pristine MPI, suggesting by the sharp peaks in the range from $10^{\circ}$ to $30^{\circ}$. And the minor diffraction peak at $10^{\circ}$ can be assigned to the in-plane structural packing motif of melamine and naphthalene units, while the peak at $26.8^{\circ}$ can be ascribed to the interlayer-stacking reflection, suggesting the possibility of at least partially layered structure in MPI. Although peaks belonging to in-plane structural packing and interlayer-stacking reflections at $10^{\circ}$ and $26.8^{\circ}$ can also be identified in the XRD pattern of Fe@MPI, the long-range crystalline order has been significantly suppressed after incorporation with Fe species. Meanwhile, no detectable reflection peak of $\mathrm{FeCl}_{3}$ or any other iron salt can be found in the XRD pattern of Fe@MPI, demonstrating the absence of pristine $\mathrm{FeCl}_{3}$ or any other iron-based inorganic crystals. Combining the XRD and FTIR results, it is rational to suppose that Fe species has been

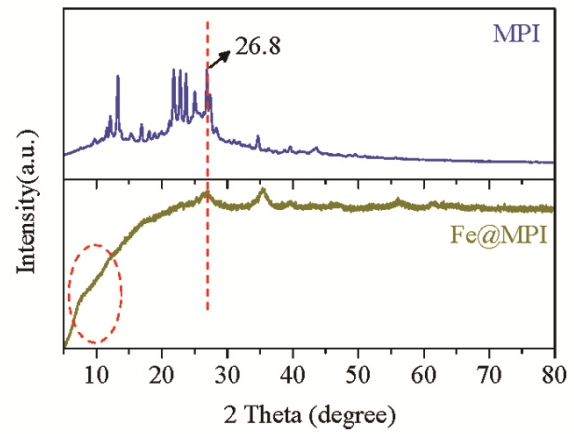

Fig. 2.XRD patterns of MPI and Fe@MPI. chemically incorporated into MPI network and thus interrupted the long-range order of the polymer network $[45,46]$.

XPS measurements were further carried out to study the electronic states and elemental compositions of Fe@MPI. Fig. 3(a) shows the overlaid XPS scans of the top layer of MPI and Fe@MPI, as well as the quantitative analysis of their elemental compositions. In the XPS scan of MPI, characteristic signals of C, $\mathrm{O}$, and $\mathrm{N}$ are found with no surprise, while in that of Fe@MPI, $\mathrm{Fe}$, besides $\mathrm{C}, \mathrm{O}$, and $\mathrm{N}$, can be detected, illustrating the successful incorporation of Fe species in MPI. However, $\mathrm{Cl}$, which origins from the precursor $\mathrm{FeCl}_{3}$, can also be observed in the XPS spectrum of Fe@MPI. The quantitative analysis of the composition of $\mathrm{Fe}$ and $\mathrm{Cl}$ revgeneeals that the molar ratio of $\mathrm{Fe} / \mathrm{Cl}$ in Fe@MPI is about 4:1, which is far beyond its molar ratio (1:3) in $\mathrm{FeCl}_{3}$, suggesting that Fe species in Fe@MPI do not in the state of $\mathrm{FeCl}_{3}$. Meanwhile, the content of Fe was tested by ICP-OES, and the ICP result showed that molar ratio of Fe was $8.15 \%$ (transformed by mass ratio), which was basically the consistent with the value obtained from XPS. The detailed Fe $2 p$ XPS signal is presented in Fig. 3(b) to investigate the ionic states of $\mathrm{Fe}$, which shows the main band of $\mathrm{Fe} 2 p_{3 / 2}$ centered at $711.2 \mathrm{eV}$ and that of Fe $2 p_{1 / 2}$ at $724.9 \mathrm{eV}$ with a splitting distance of $12.7 \mathrm{eV}$. Meanwhile, the branching ratio of $2 p_{3 / 2}: 2 p_{1 / 2}$ can be calculated from the area ratio of their peaks, which is 1:0.5 in this case. The band positions and branching ratio of $\mathrm{Fe}$ $2 p_{3 / 2}$ and $2 p_{1 / 2}$ in Fe@MPI is in perfect agreement with the characteristic values of $\mathrm{Fe}(\mathrm{III})[47,48]$. Additionally, a $\mathrm{Fe}^{3+} s p_{3 / 2}$ satellite peak around $719.0 \mathrm{eV}$ confirms the presence of Fe(III) in the surface of Fe@MPI [49,50]. 

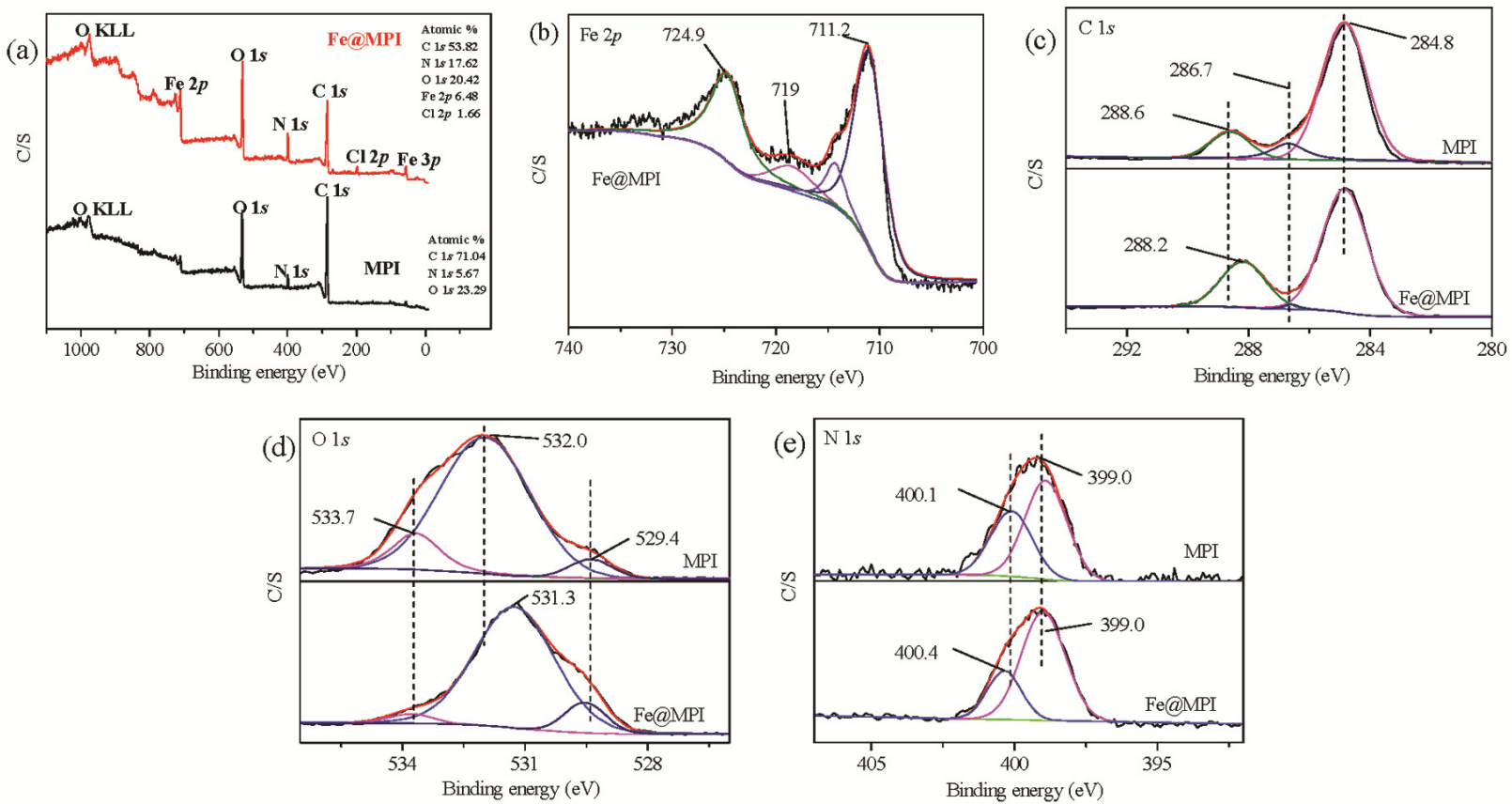

Fig. 3. XPS survey spectra (a) and high-resolution XPS spectra of Fe $2 p$ (b), C $1 s$ (c), $01 s$ (d) and N $1 s$ (e) of MPI and Fe@MPI.

C $1 s$ core-level XPS spectra for MPI and Fe@MPI as well as the spectra of $01 s$ and $\mathrm{N} 1 \mathrm{~s}$ are presented in Fig. 3(c)-(e) to investigate the coordination between Fe(III) and MPI framework. As shown in Fig. 3(c), the dominating peaks at 284.8, 286.7 and $288.6 \mathrm{eV}$ in the spectrum of MPI are ascribed to the carbon atoms in the naphthalene rings, the carbonyl groups and the triazine units, respectively [40]. After the cooperating of Fe(III) cations, the peak of carbon atom in the triazine units at $288.6 \mathrm{eV}$ was shifted to lower binding energy (288.2 eV), and the peak of carbonyl carbon at $286.7 \mathrm{eV}$ was reduced in intensity, confirming the evidences from FTIR for the successful cooperating of $\mathrm{Fe}$. And the shifts of $\mathrm{N}$ core-level binding energy, as respectively shown in Fig. 3(c), could also be ascribed the Fe cooperating effect [51]. Meanwhile, a reduction in the 0 binding energy peak centered at 533.7, designated to carbonyl oxygen atom in the residual anhydride groups [52], was noticed, which coincided well with the FT-IR analysis that the cooperating of Fe(III) led to reduce the amount of residual anhydride groups.

SEM and TEM measurements were conducted to investigate the morphology of Fe@MPI. Similar to the morphology of polyimide network which we have previously reported [32], the Fe@MPI exhibits porous structure with rough surface (Fig. 4(a)). Moreover, the porous morphology of Fe@MPI can be seen more clearly from the TEM images (Fig. 4(b)-(d)). From the Fig. 4(c)-(d), no visible particles or obvious crystallite structure can be attributed to Fe species in the HRTEM image, which gives direct evidence that Fe(III) cations are cooperated in MPI network rather than the formation of $\mathrm{Fe}$ or $\mathrm{FeCl}_{3}$ particles. The intrinsic micro-porosity of Fe@MPI was investigated by the BET nitrogen adsorption method (Fig. 4(e)-(f)), which shows a BET surface area of $30.6 \mathrm{~m}^{2} \mathrm{~g}^{-1}$ with a total pore volume ( $\left.V_{\text {total }}\right)$ of $0.027 \mathrm{~cm}^{3} \mathrm{~g}^{-1}$. Meanwhile, it can be observed the
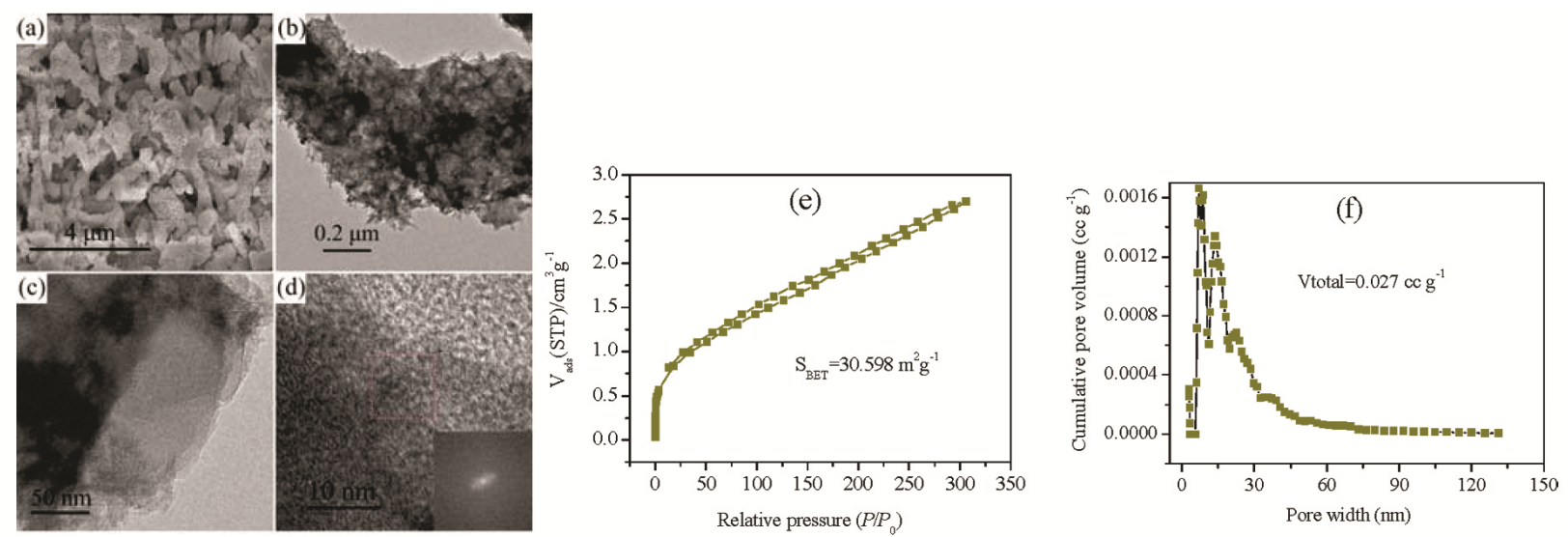

Fig. 4. SEM (a) and TEM (b) and HRTEM (c-d) images and the insert is FFT of the chosen area of Fe@MPI; (e) $\mathrm{N}_{2}$ adsorption-desorption isotherm of Fe@MPI at $77 \mathrm{~K}$; (f) the corresponding pore size distribution. 

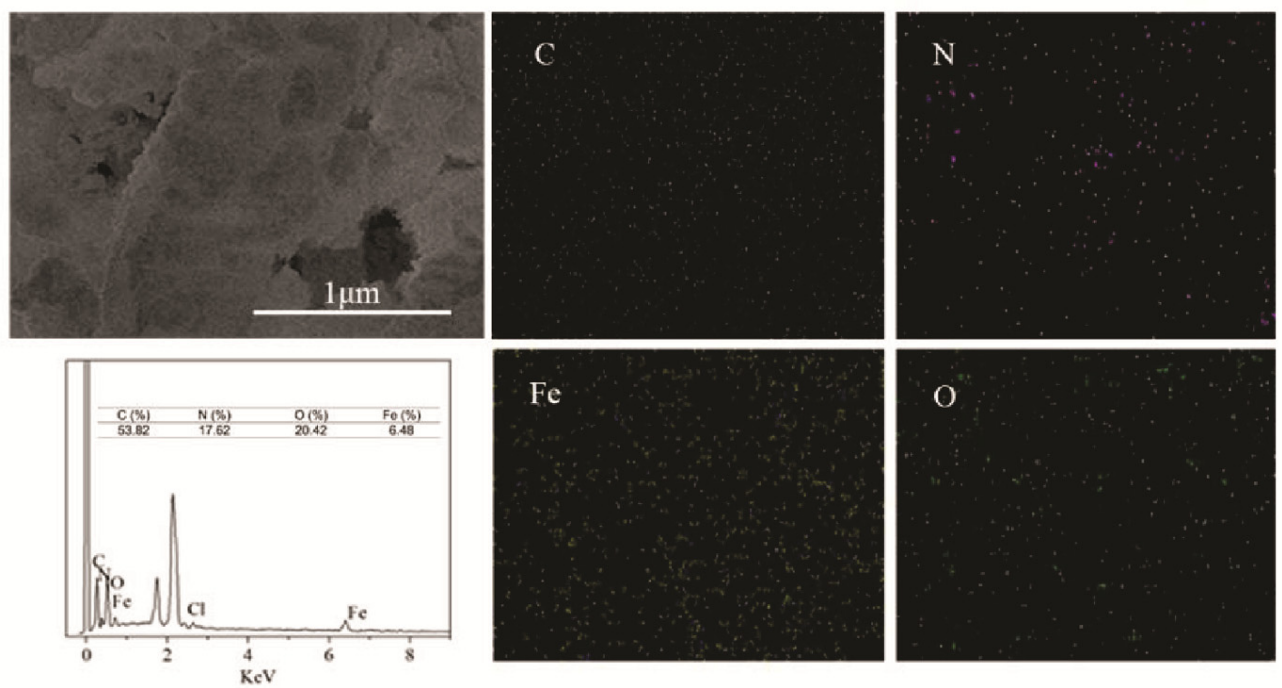

Fig. 5. SEM-EDS mapping images of Fe@MPI for C, N, Fe and O elements.

presence of a sharp uptake at a relative pressure of $P / P_{0}<0.1$ in the isotherm, indicating that Fe@MPI has micro- and mesopores. By fitting the nonlocal density functional theory (NLDFT) model to the nitrogen adsorption data, the pore size distribution for Fe@MPI were achieved and presented in Fig. 4(f). Two main peaks at 7 and $12 \mathrm{~nm}$ can be observed from the inset, which agree perfectly with the shape of the $\mathrm{N}_{2}$ isotherm.

The distribution of Fe(III) species in MPI framework was investigated by the SEM-EDX method. Figure 5 shows the EDX spectrum as well as the C, N, $\mathrm{O}$ and Fe elemental mappings with distinct color contrast, which indicate the even distribution of Fe species and the main elemental species in MPI including C, N and $\mathrm{O}$. This result clearly suggests the homogeneous incorporation of Fe species within MPI framework. Moreover, the molar ratio of $\mathrm{Fe} / \mathrm{Cl}$ calculated from the EDX result is 3.9:1, which is extremely close to the value calculated from XPS (4:1), suggesting the absence of $\mathrm{FeCl}_{3}$ and the coordination of $\mathrm{Fe}(\mathrm{III})$ cations with MPI network. Combining the results from EDX, FTIR, XRD, and XPS, it is rational to conclude that Fe species have been homogeneously incorporated into the MPI network without the formation of $\mathrm{FeCl}_{3}$ or any other Fe(III) salts [53].

\subsection{Photoelectric properties}

UV-vis absorption spectroscopy was carried out to evaluate

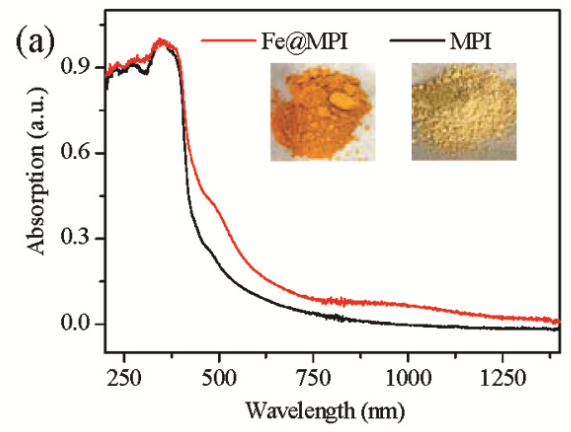

the optical properties of MPI and Fe@MPI, and the spectra are presented in Fig. 6(a). Digital photos of both MPI and Fe@MPI are also presented in the inset in Fig. 6(a) for visual assessment of their absorption. Both Fe@MPI and MPI can absorb visible light, but Fe@MPI (orange-yellow) exhibits superior ability to harvest longwave photons in comparison with the pristine MPI (light-yellow). The formation of Fe-polyimide coordination complexes within MPI enables a broad absorption from $200 \mathrm{~nm}$ to near infrared region $(\sim 1250 \mathrm{~nm})$, and simultaneously enhances its absorption intensity over that of pristine MPI. The optical properties of Fe@MPI imply an improved photocatalytic activity. And transient photocurrent tests were carried out to evaluate the photocatalytic activity of Fe@MPI, and the results are shown in Fig. 6(b). For both MPI and Fe@MPI, no current response could be detected in the dark, but obvious photocurrent responses were recorded when the MPI and Fe@MPI working electrodes were irradiated by visible-light. These results illustrate that both MPI and Fe@MPI are photoactive materials which can harvest protons in visible-light range to generate electron-hole pairs. Meanwhile, we can observe a significant increase $(\sim 3.5$ times) in the photocurrent intensity of Fe@MPI in comparison with MPI. This result demonstrates that chelating Fe(III) species into MPI network can efficiently enhance its light harvesting ability and simultaneously inhibit the recombination of the photogenerated electron-hole pairs. Thus,

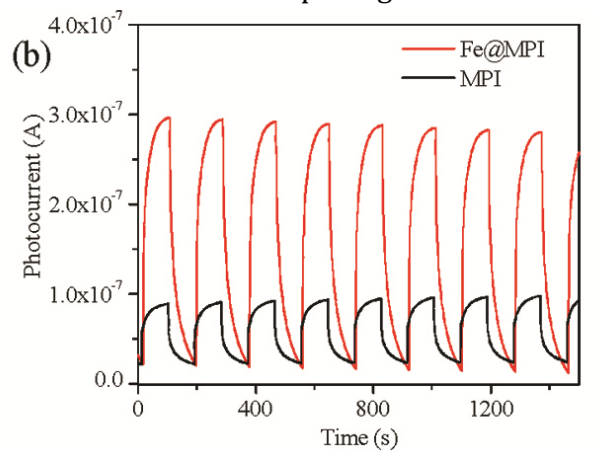

Fig. 6. (a) UV-vis absorption spectra and photograph (inset) of MPI and Fe@MPI; (b) photocurrent transient response of MPI and Fe@MPI. 
an improvement in photocatalytic performance for Fe@MPI can be expected.

\subsection{Photocatalytic performance}

To evaluate the catalytic activity, Fe@MPI catalyzed radical polymerization of methyl methacrylate (MMA) under visible light irradiation was carried out in the presence of triethylamine $\left(\mathrm{Et}_{3} \mathrm{~N}\right)$ as a sacrificial electron donor. Meanwhile, radical polymerizations of MMA under identical conditions except for the absence of photocatalyst or using MPI or $\mathrm{FeCl}_{3}$ as photocatalyst were carried out as the controls, and the results are presented in Fig. 8(a). It is worth to notice here that the temperature was strictly maintained at $30 \pm 0.5{ }^{\circ} \mathrm{C}$ and UV-light below $420 \mathrm{~nm}$ was completely filtered in all cases to eliminate the self-polymerization induced by heat or UV-light. The blank experiment (Fig. 8(a)) which was carried out in the absence of photocatalyst confirmed the elimination of self-polymerization, as only trace amount of MMA was converted to polymer after 6 $\mathrm{h}$ of reaction. Although Fe(III) is an efficient oxidant which can initiate the radical polymerization of various vinyl monomers in a water-borne system by coupling with specific reductants like thiourea [54], $\mathrm{FeCl}_{3}$ shows very limited activity to initiate the polymerization MMA in this case, even in the presence of triethylamine, and only about $5.6 \%$ of monomer conversion has been achieved in $6 \mathrm{~h}$. One possible reason for this result may be ascribed to the extremely poor ionization efficiency for $\mathrm{FeCl}_{3}$ in dioxane, a nonpolar solvent. In comparison with $\mathrm{FeCl}_{3}$, both pristine MPI and Fe(III) doping MPI (Fe@MPI) exhibit superior photocatalytic activities toward the radical polymerization of MMA, with MMA conversions of $14.9 \%$ and $21.7 \%$, respectively. The successful conversions of monomer to polymer were confirmed by GPC measurements, which were shown in Table 1. By using MPI as photocatalyst, PMMA with a number average molecular weight $(\mathrm{Mn})$ of $12.1 \times 10^{4} \mathrm{~g} \mathrm{~mol}^{-1}$ and molecular weight distribution (MWD) of 2.0 could be obtained, while using Fe@MPI as photocatalyst, PMMA with Mn of $31.3 \times$ $10^{4} \mathrm{~g} \mathrm{~mol}^{-1}$ and MWD of 2.2 could be obtained. Combining the results from Fig. 8(a) and Table 1, it is rational to deduce that: (1) MPI plays the crucial role in converting visible light energy to propagating carbon radicals; (2) the cooperating of Fe(III) can facilitate the converting process and thus enhance the photocatalytic active of Fe@MPI due to the improved separa-
Table 1

Results from photopolymerizations of MMA using different catalysts.

\begin{tabular}{lccccc}
\hline No. & Catalyst & {$[\mathrm{M}]_{0} /[\mathrm{C}]_{0}$} & Conv. $(\%)$ & $\mathrm{Mn}\left(10^{4} \mathrm{~g} \mathrm{~mol}^{-1}\right)$ & $\mathrm{MWD}$ \\
\hline 1 & - & $100 / 0$ & 0.2 & - & - \\
2 & $\mathrm{FeCl}_{3}$ & $100 / 1$ & 5.6 & - & - \\
3 & $\mathrm{MPI}$ & $100 / 1$ & 14.9 & 12.1 & 2.0 \\
4 & $\mathrm{Fe} @ \mathrm{MPI}$ & $100 / 1$ & 21.7 & 31.3 & 2.2 \\
\hline
\end{tabular}

tion efficiency of photo-generated electron-hole pairs.

Figure $8(\mathrm{~b})$ illustrates the comparison of polymerization behaviors between the presence and absence of triethylamine, the sacrificial electron donor. Like similar results reported previously [39,55], an amine electron donor, which is triethylamine in this case, is indispensable for the visible-light driven polymerization induced by an inorganic or organic semiconductor. Apart from the fact that triethylamine as an effective electron donor can enhance the separation efficiency of the photo-generated electron-hole pairs and further facilitate the generation of carbon radicals, triethylamine can also initiate the radical polymerization since active free radical can be formed when triethylamine captures photo-generated hole from Fe@MPI, following oxidation and deprotonation [56]. The radical polymerization process has been partially evidenced by the radical quenching experiment in the Fig. 8(b). Hydroquinone, as one of the most effective free radical quenching agents, were added in the polymerization system, and its influence on the polymerization behavior was also presented in Fig. 8(b). The monomer conversion sharply decreased from $21.7 \%$ to $6.8 \%$ when $1 \%$ (based on the total amount of MMA) of hydroquinone was introduced to the polymerization system, elucidating clearly the pivotal role of free radical in the polymerization. In order to evaluate the redox ability of Fe@MPI, its band structure was characterized by the following methods. The tauc plot of Fe@MPI was shown in Fig. 7(a), corresponding to bandgap energies of $2.87 \mathrm{eV}$. To further determine the relative positions of the valence band (VB) and conduction band (CB) edges, the electrochemical Mott-Schottky experiment was performed (Fig. 7(b)). The positive slopes of the plots suggested that Fe@MPI was n-type semiconductors. And the flat band position of n-type semiconductors is closer to their CB position. From the intercept of the abscissa, the CB minimum was estimated to be $-0.25 \mathrm{~V}$ for Fe@MPI vs. SCE, which was translated to a normal hydrogen electrode for $-0.01 \mathrm{~V}$ for Fe@MPI [57].
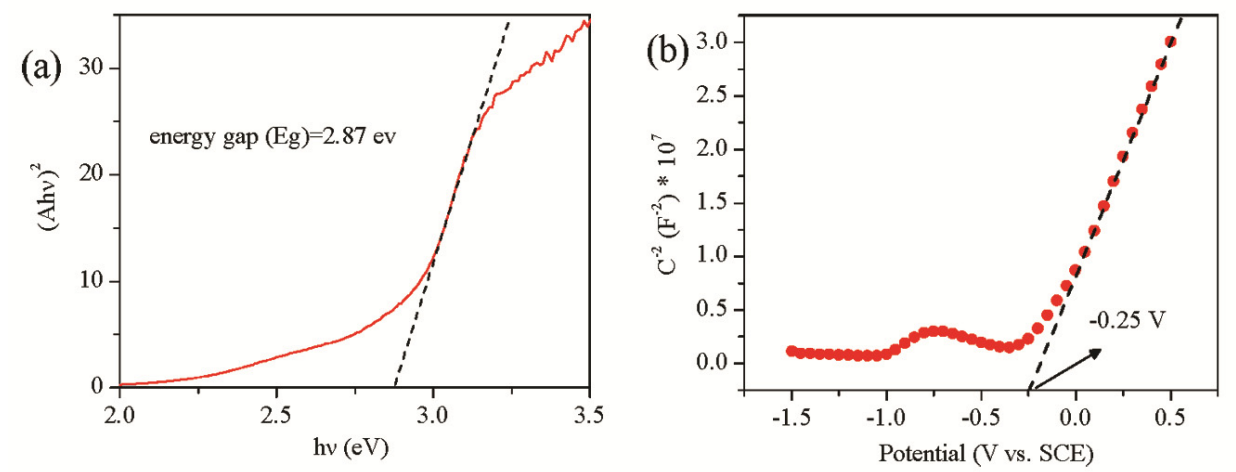

(c)

V vs. $\mathrm{NHE}(\mathrm{pH}=0)$

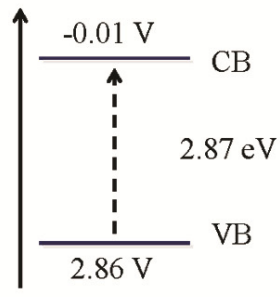

Fig. 7. The tauc plot (a) and the Mott-Schottky plot (b) of Fe@MPI, (c) The band structure of Fe@MPI. 

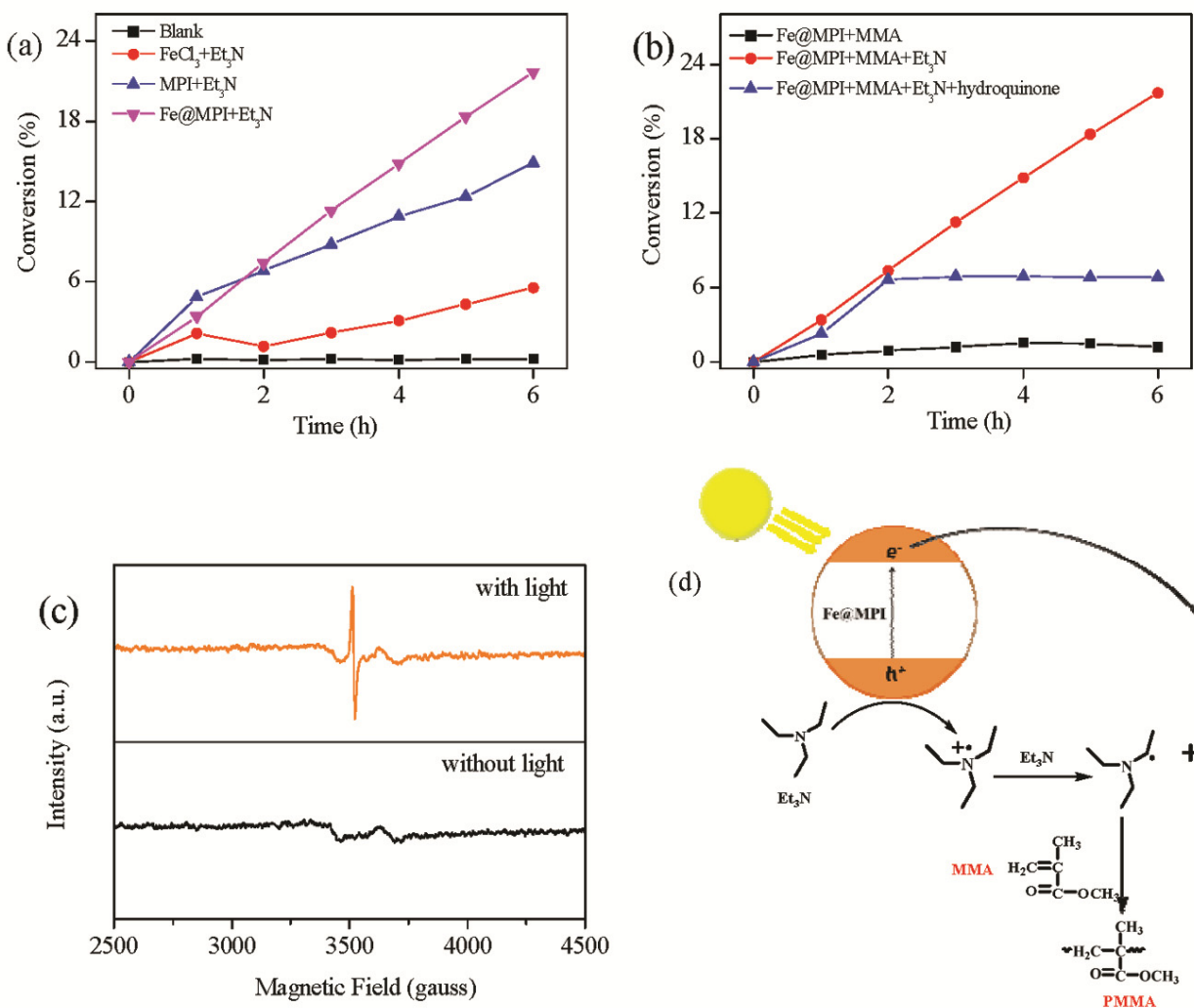

(d)

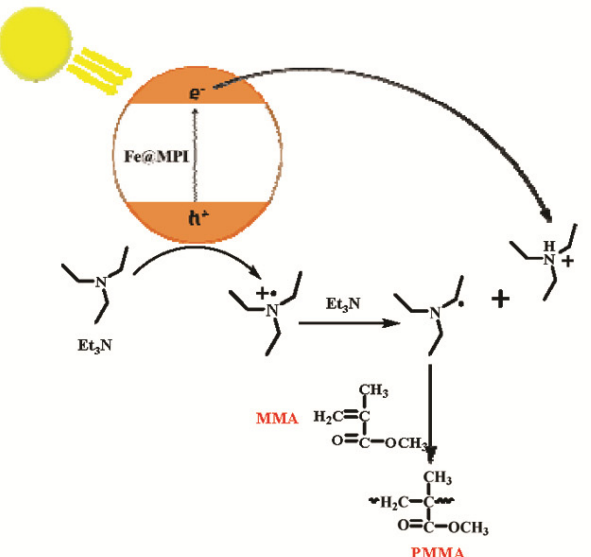

Fig. 8. (a) The monomer conversion vs. time plots for the polymerization of MMA in the presence of different catalyst; (b) the radical quenching experiments of Fe@MPI-induced photo-polymerization; (c) EPR spectra of the .dioxane solution of Fe@MPI/triethylamine before and after light irradiation; (d) schematic diagram of the radical generation mechanism during the photo-irradiation of Fe@MPI in the presence of triethylamine (Et ${ }_{3} \mathrm{~N}$ ).

These data, combined with the bandgap energy, allowed us to calculate the VB edge of Fe@MPI at 2.86 V in the Fig. 7(c). In previous reports, the reduction potential of triethylamine was $0.96 \mathrm{~V}$ (vs SCE) [58], which less than the position of VB. Thus, triethylamine can be converted into triethylamine radical cation by reducing photogenerated hole. EPR measurement of Fe@MPI was conducted before and after light irradiation to support the generation of free radicals. Without light irradiation, EPR spectrum of the dioxane solution of Fe@MPI/triethylamine displays very week signals of oxygen vacancy at $g$ value of $2.0400[59,60]$ (Fig. 8(c)), suggesting the absence of free radical species. However, after light irradiation, a typical radical signal [61] at g value of 1.9922 can be witnessed, supporting the formation of radical species in the present initiating system [62]. Combining the results from EPR and radical quenching experiments, we propose the following mechanism for visible-light driven radical polymerization using Fe@MPI as photocatalyst (Fig. 8(d)): upon light irradiation in the presence of triethylamine as an electron donor, Fe@MPI is excited by the absorbed photons, and photogenerated electrons can be easily transferred to Fe(III) cations coordinated MPI due to the metal-to-ligand charge transfer. Then the excited state Fe@MPI* is reductively quenched by triethylamine to generate radical cations. And the radical cations further abstract hydrogen from another amine, leading to the formation of initiating radicals for the radical polymerization of MMA.

The recyclability of Fe@MPI was evaluated by repeatedly initiating the polymerization of MMA, as shown in Fig. 9. After four initiating-separating cycles, Fe@MPI retains essentially unchanged photocatalytic performance for the radical polymerization with a monomer conversion of $20 \%$, which reaches more than $92 \%$ of its initial activity. The structural and morphological stability of Fe@MPI during recycling process were also investigated and the results are shown in Fig. 10 and Table 2. The FTIR spectrum and XRD pattern of Fe@MPI after 4 initiating-separating cycles are nearly identical to the original ones, suggesting the well-retaining structures of Fe@MPI during recycling tests. It is noteworthy that both the position and the intensity of the broad peak of $\mathrm{Fe}-\mathrm{N}$ chelating bond at $610-690 \mathrm{~cm}^{-1}$ have been retained after recycling, suggesting

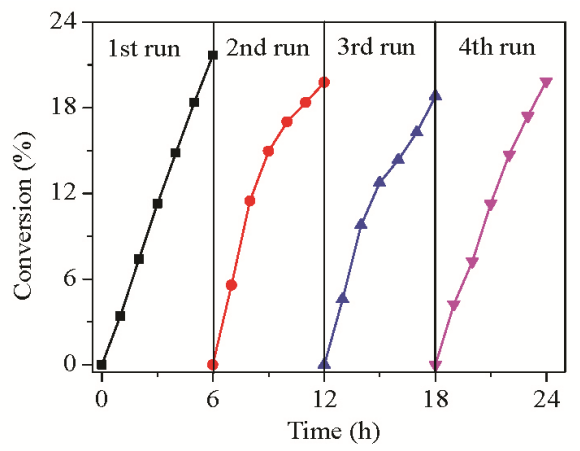

Fig. 9. Four successive photopolymerization kinetic plots of MMA using Fe@MPI as photocatalyst. 

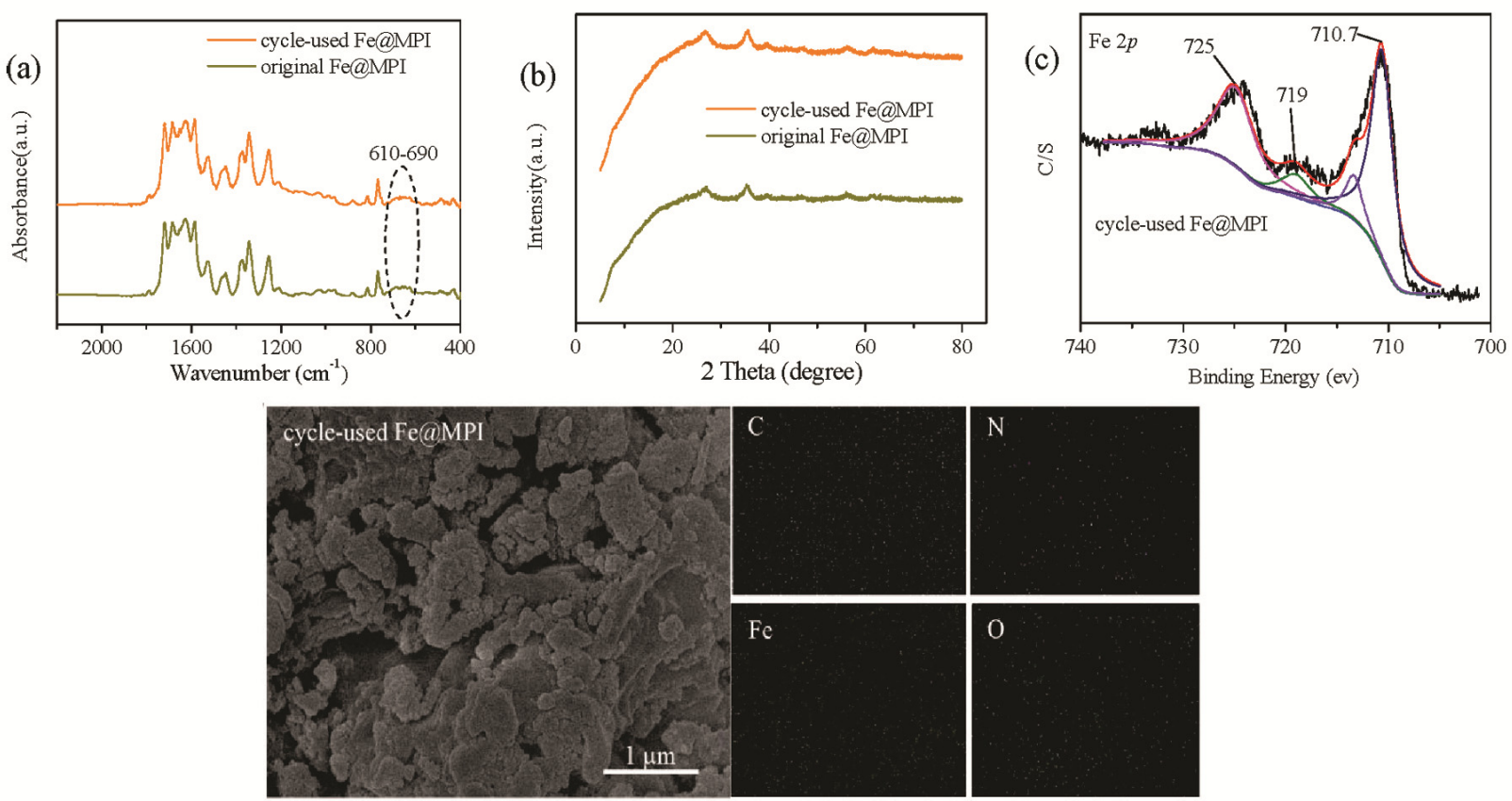

Fig. 10. FT-IR (a) and XRD (b) patterns of original and cycled-used Fe@MPI; (c) Fe $2 p$ core-level XPS spectra of cycle-used Fe@MPI; (d) SEM-EDX mapping images of cycle-used Fe@MPI for C, N, Fe and $\mathrm{O}$ elements.

the stability of the cooperated Fe(III) cations. This result has also been confirmed by the SEM-EDX analysis, as shown in Fig. 10(d) and Table 2. The dispersion and atomic percentage of $C$, $\mathrm{N}, \mathrm{O}$ and $\mathrm{Fe}$ in the repeatedly-used Fe@MPI are nearly identical to its original results. Moreover, XPS measurement of cycle-used Fe@MPI was carried out (Fig. 10(c)), and the result show that the electronic states of Fe@MPI does not change. Taking the atomic percentage of Fe for instance, it dropped very slightly from $6.48 \%$ to $6.23 \%$ after 4 recycling tests, avoiding the $\mathrm{Fe}(\mathrm{III})$ species leaching from MPI framework which may lead to poor recyclability for its photocatalytic performance.

\section{Conclusions}

We demonstrate the successful synthesis of Fe(III) chelating polyimide network (Fe@MPI) and its use as heterogeneous photocatalyst for photoinduced radical polymerization of MMA by coupling with triethylamine as the sacrificial electron donor. The chelating of Fe(III) to MPI offers broad spectral response from ultraviolet to NIR wavelengths and the promoted separation efficiency of photogenerated electron-hole pairs, and thus imparts significant improvement in the photocatalytic activity toward visible light driven radical polymerization, producing

Table 2

Elemental percentage of C, N, 0 and Fe present in Fe@MPI before and after 4 successive recycle runs.

\begin{tabular}{lcccc}
\hline Sample & C (\%) & N (\%) & O (\%) & Fe (\%) \\
\hline original Fe@MPI & 53.82 & 17.62 & 20.42 & 6.48 \\
cycle-used Fe@MPI & 54.89 & 17.03 & 20.67 & 6.23 \\
\hline
\end{tabular}

poly(methyl methacrylate) with Mn up to $313 \times 10^{4} \mathrm{~g} \mathrm{~mol}^{-1}$. Owing to the advantages of Fe@MPI like its stable structure and heterogeneous nature, Fe@MPI photocatalyst can be easily regenerated from the polymerization system without significant leaching of $\mathrm{Fe}(\mathrm{III})$ and losing of photocatalytic performance under experiment conditions. Attractive features of this system include the facile and scalable synthesis strategy to photoactive MPI network, stable structure of Fe@MPI in organic environment, easy regeneration from polymerization system and no use of expensive compounds, offering it the potential to broad applications involving photopolymerization.

\section{References}

[1] P. Nesvadba, Ency. Radi. Chem., Bio. Mater., 2012.

[2] D. Gust, T. A. Moore, A. L. Moore, Acc. Chem. Res., 2009, 42, 1890-1898.

[3] H. Du, Y. N. Liu, C. C. Shen, A. W. Xu, Chin. J. Catal., 2017, 38, 1295-1306.

[4] S. Dadashi-Silab M. Atilla Tasdelen, A. M. Asiri, S. Bahadar Khan, Y. Yagci, Macromol. Rapid Commun., 2014, 35, 454-459.

[5] L. Hou, L. Wang, N. Zhang, Z. G. Xie, D. W. Dong, Polym. Chem., 2016, 7, 5828-5834.

[6] P.Zhang, X. W. Lou, Adv. Mater., 2019, 31, 1900281.

[7] P. Zhang, T. Wang, X. X. Chang, J. L. Gong, Acc. Chem. Res., 2016, 49, 911-921.

[8] X. Wang, R. R. Valiev, T. Y. Ohulchanskyy, H. Ågren, C. Yang, G. Chen, Chem. Soc. Rev., 2017, 46, 4150-4167.

[9] X. Huang, T. R. Quinn, K. Harms, R. D. Webster, L. Zhang, O. Wiest, E. Meggers, J. Am. Chem. Soc., 2017, 139, 9120-9123.

[10] C. X. Li, W. S. Lu, X. M. Zhou, M. M. Pang, X. L. Luo, Anal. Chem., 2018, 90, 14239-14246. 


\section{Graphical Abstract}

Chin. J. Catal., 2021, 42: 141-151 doi: 10.1016/S1872-2067(20)63610-5

\section{A novel iron-chelating polyimide network as a visible-light-driven catalyst for photoinduced radical polymerization}

Gang Ding, Qin Wang, Fei Liu, Yi Dan *, Long Jiang * Sichuan University;

Southwest University of Science and Technology

In this study, $\mathrm{Fe}(\mathrm{III})$ chelating melamine polyimide network (Fe@MPI) has been successfully synthesized and served as a heterogeneous catalyst for visible light driven radical polymerization of MMA. Fe@MPI can be easily separated from the polymerization solution due to its heterogeneous nature, and reused without losing its photocatalytic performance.

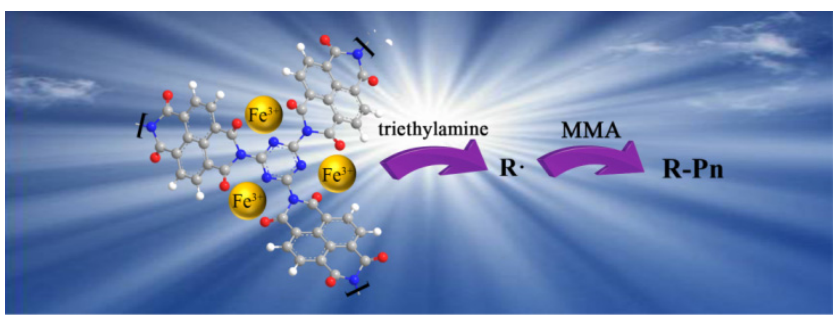

[11] Q. M. Kainz, C. D. Matier, A. Bartoszewicz, S. L. Zultanski, J. C. Peters, G. C. Fu, Science, 2016, 351, 681-684.

[12] Y. Peng, L. Shang, Y. Cao, G. I. N. Waterhouse, C. Zhou, T. Bian, L. Z. Wu, C. H. Tung, T. Zhang, Chem. Commun., 2015, 51, 12556-12559.

[13] C. L. Yu, W. Q. Zhou, J. C. Yu, H. Liu, L. F. Wei, Chin. J. Catal., 2014, $35,1609-1618$.

[14] W. B. Wu, S. D. Xu, G. B. Qi, H. Zhu, F. Hu, Z. T. Liu, D. Q. Zhang, B. Liu, Angew. Chem. Int. Ed., 2018, 58, 3062-3066.

[15] H. J. Han, M. Fu, Y. L. Li, W. Guan, P. Lu, X. L. Hu, Chin. J. Catal,, 2018, 39, 831-840

[16] S. W. Cao, J. X. Low, J. G. Yu, M. Jaroniec, Adv. Mater, 2015, 27, 2150-2176.

[17] A. Kabumoto, S. Yanagida, K. Mizumoto, C. Pac, K. Yoshinob, J. Chem. Soc. Chem. Commun., 1985, 474-475.

[18] L. Chen, Y. Honsho, S. Seki, D. L. Jiang, J. Am. Chem. Soc., 2010, 132, 6742-6748.

[19] R. S. Sprick, J. X. Jiang, B. Bonillo, S. Ren, T. Ratvijitvech, P. Guiglion, M. A. Zwijnenburg, D. J. Adams, A. I. Cooper, J. Am. Chem. Soc., 2015, 137, 3265-3270.

[20] S. W. Cao, J. G. Yu, J. Phys. Chem. Lett., 2014, 5, 2101-2107.

[21] Y. Zheng, L. H. Lin, B. Wang, X. C. Wang, Angew. Chem. Int. Ed., 2015, 54, 12868-12884.

[22] L. Y. Li, Z. M. Zhou, L. Y. Li, Z. Y. Zhuang, J. H. Bi, J. H. Chen, Y. Yu, J. G. Yu, ACS Sustainable Chem. Eng., 2019, 7, 18574-18581.

[23] C. Cheng, X. C. Wang, F. Wang, Appl. Surf. Sci., 2019, 495, 143537.

[24] H. Hu, Q. Q. Yan, R. Ge, Y. A. Gao, Chin. J. Catal., 2018, 39, 1167-1179.

[25] Q. L. Xu, B. C. Zhu, B. Cheng, J. G. Yu, M. H. Zhou, W. K. Ho, Appl. Catal. B, 2019, 225, 117770.

[26] F. Vilela, K. Zhang, M. Antonietti, Energy Environ. Sci., 2012, 5, 7819-7832.

[27] S. Chu, Y. Wang, Y. Guo, P. Zhou, H. Yu, L. L. Luo, F. Kong, Z. G. Zou, J. Mater. Chem., 2012, 22, 15519-15521.

[28] S. Chu, Y. Wang, C. C. Wang, J. C. Yang, Z. G. Zou, Int. J. Hydrogen Energy, 2013, 38, 10768-10772.

[29] X. Q. Fan, L. X. Zhang, R. L. Cheng, M. Wang, M. L. Li, Y. J. Zhou, J. L. Shi, ACS Catal., 2015, 5, 5008-5015.

[30] Y. B. Li, Z. L. Jin, L. J. Zhang, K. Fan, Chin. J. Catal., 2019, 40, 390-402.
[31] Q. Yan, G. F. Huang, D. F. Li, M. Zhang, A. L. Pan, W. Q. Huang, J. Mater. Sci. Technol., 2018, 34, 2515-2520.

[32] Q. Wang, J. L. Zhang, Y. Y. Yu, Y. Dan, L. Jiang, New J. Chem., 2018, $42,12205-12211$.

[33] S. C. Yan, S. B. Lv, Z. S. Li, Z. G. Zou, Dalton Trans., 2010, 39, 1488-1491.

[34] Y. J. Ren, D. Q. Zeng, W. J. Ong, Chin. J. Catal., 2019, 40, 289-319.

[35] Y. A. Liu, L. B. Ma, C. C. Shen, X. Wang, X. Zhou, Z. W. Zhao, A. W. Xu, Chin. J. Catal., 2019, 40, 168-176.

[36] F. Liu, T. P. Nguyen, Q. Wang, F. Massuyeau, Y. Dan, L. Jiang, App. Surf. Sci., 2019, 496, 143653.

[37] K. Sun, L. F. Wang, C. Z. Wu, J. P. Deng, K. Pan, Adv. Mater. Interfaces, 2017, 4, 1700845.

[38] W. L. Yu, S. Zhang, J. X. Chen, P. F. Xia, M. H. Richter, L. F. Chen, W. Xu, J. P. Jin, S. L. Chen, T. Y. Peng, J. Mater. Chem. A, 2018, 6, 15668-15674.

[39] B. Kiskan, J. S. Zhang, X. C. Wang, M. Antonietti, Y. Yagci, ACS Macro. Lett., 2012, 1, 546-549.

[40] Y. Z. Liao, J. Weber, C. F. J. Faul, Macromolecules, 2015, 48, 2064-2073.

[41] N. E. Mircescu, M. Oltean, V. Chis, N. Leopold, Vib. Spectrosc., 2012, $62,165-171$

[42] M. R. Liebl, J. Senker, Chem. Mater., 2013, 25, 970-980.

[43] S. Nayak, L. Mohapatra, K. Parida, J. Mater. Chem. A, 2015, 3, 18622-18635.

[44] D. Predoi, Dige. J. Nano. Bio., 2007, 2, 169-173.

[45] E. L. Spitler, B. T. Koo, J. L. Novotney, J. W. Colson, F. J. Uribe-Romo, G. D. Gutierrez, P. Clancy, W. R. Dichtel, J. Am. Chem. Soc., 2011, 133, 19416-19421.

[46] Y. Zhang, T. Mori, L. Niu, J. Ye, Energy Environ. Sci., 2011, 4, 4517-4521.

[47] J. A. Zazo, J. Bedia, C. M. Fierro, G. Pliego, J. A. Casas, J. J. Rodriguez, Catal. Today, 2012, 187, 115-121.

[48] A. P. Grosvenor, B. A. Kobe, M. C. Biesinger, N. S. McIntyre, Surf. Interface Anal., 2004, 36, 1564-1574.

[49] T. Yamashita, P. Hayes, Appl. Surf. Sci., 2008, 254, 2441-2449.

[50] A. Rey, M. Faraldos, J. A. Casas, J. A. Zazo, A. Bahamonde, J.J. Rodriguez, Appl. Catal. B-Environ., 2009, 86, 69-77.

[51] S. Z. Hu, R. R. Jin, G. Lu, D. Liu, J. Z. Gui, RSC Adv., 2014, 4, 24863-24869. 
[52] Y. Tong, F. Nicolas, S. Kubsky, H. Oughaddou, F. Sirotti, V. Esaulov, A. Bendounan, J. Phys. Chem. C, 2017, 121, 5050-5057.

[53] X. F. Song, H. Tao, L. X. Chen, Y. Sun, Mater. Lett., 2014, 116, 265-267.

[54] A. Hebeish, S. H. Abdel-Fattah, A. Bendak, Angew. Makromol. Chem., 1974, 37, 11-25.

[55] M. L. Allegrezza, Z. M. DeMartini, A. J. Kloster, Z. A. Digby, D. Konkolewicz, Polym. Chem., 2016, 7, 6626-6636.

[56] R. Ojah, S. K. Dolui, Sol. Energ. Mat. Sol. C., 2006, 90, 1615-1620.

[57] J. W. Fu, Q. L. Xu, J. X. Low, C. J. Jiang, J. G. Yu, Appl. Catal. B, 2019, $243,556-565$.
[58] X. H. Ci, R. S. Da Silva, J. L. Goodman, D. E. Nicodem, D. G. Whitten, J. Am. Chem. Soc., 1988, 110, 8548-8550.

[59] L. Kong, C. H. Wang, F. X. Wan, H. Zheng, X. T. Zhang, Appl. Surf. Sci, 2017, 396, 26-35.

[60] H. Q. Tan, Z. Zhao, W. B. Zhu, E. N. Coker, B. S. Li, M. Zheng, W. X. Yu, H. Y. Fan, Z. C. Sun, ACS Appl. Mater. Interfaces, 2014, 6, 19184-19190.

[61] B. Z. Lü, Y. F. Chen, P. Y. Li, B. Wang, K. Müllen, M. Z. Yin, Nat. Commun., 2019, 10, 767.

[62] X. D. Liu, L. F. Zhang, Z. P. Cheng, X. L. Zhu, Polym. Chem., 2016, 7, 689-700.

\title{
可见光响应 $\mathbf{F e}^{3+}$-聚酰亚胺网络的合成及光诱导自由基聚合
}

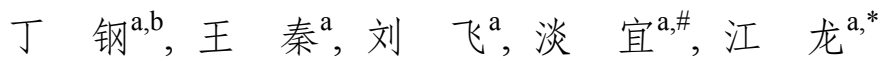 \\ a 高分子材料工程国家重点实验室(四川大学), 四川大学高分子研究所, 四川成都610065

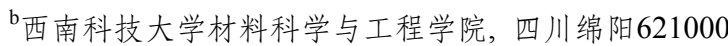

\begin{abstract}
摘要: 将清洁、安全的太阳能(尤其是可见光)转化为化学能以合成高分子材料, 一直是光催化领域的研究热点和难点. 其关 键问题是发展新型光催化材料, 提升其在高分子合成环境下的光催化活性及稳定性. 由于共轭微孔聚合物网络的独特优 点, 例如光电性能易调控、比表面积高以及结构相对稳定等, 在光催化领域应用日益广泛. 与其它共轭微孔聚合物网络相 比, 聚酰亚胺网络具有更高的光稳定性和耐化学腐蚀能力; 同时, 可用于合成聚酰亚胺网络的单体丰富, 合成方法可靠, 易 于从分子层面调控其光电活性, 提升其光催化活性. 由于以上优点, 基于聚酰亚胺网络的光催化体系在光诱导合成高分子 材料领域展现出良好的应用前景. 然而在实际应用中, 聚酰亚胺网络却面临光催化活性不足的困扰. 为解决此问题, 本研 究组曾设计, 合成了以 $4,4^{\prime}, 4^{\prime \prime}$-三氨基三苯胺为核的聚酰亚胺网络, 利用 $4,4^{\prime}, 4^{\prime \prime}$-三氨基三苯胺的给电子能力, 促进聚酰亚胺 网络中光生电子/空穴对的分离, 有效提升了聚酰亚胺网络在可见光作用下对水相中有机污染物的光降解效率.

在已有工作的基础上, 本文设计、合成出一种新型聚酰亚胺网络, 并通过配位作用, 在聚酰亚胺网络网络中引入 $\mathrm{Fe}^{3+}$ 离 子掺杂, 提升其光催化性能, 在有机环境中实现可见光诱导自由基聚合. 首先, 以三聚氧胺为电子给体单元, 以 $1,4,5,8$-䒺四 甲酸二䣶为电子受体单元, 通过酰亚胺缩聚反应构建出含电子给体-受体交替结构的聚酰亚胺网络(MPI); 然后, 通过浸渍 法将 $\mathrm{Fe}^{3+}$ 离子引入到MPI网络内, 制备出 $\mathrm{Fe}^{3+}$-聚酰亚胺网络( $\mathrm{Fe} @ \mathrm{MPI}$ ). 通过傅里叶变换红外光谱, 粉末 $\mathrm{X}$ 射线衍射 $\mathrm{XRD}$ )和 X射线光电子能谱对 $\mathrm{Fe} @ M$ MI的结构进行表征. 结果显示, $\mathrm{Fe}^{3+}$ 主要通过配位键的形式与MPI网络结合. 同时, 结合XRD谱 图与扫描电子显微镜和透射电子显微镜结果可见, $\mathrm{Fe}^{3+}$ 并非以氧化物或其它铁盐的形式简单地沉积在聚酰亚胺网络上, 而 是以 $\mathrm{Fe}^{3+}$-MPI配位作用均匀分布在MPI网络内. 此外, XRD及氮气吸附实验结果表明, 引入 $\mathrm{Fe}^{3+}$ 会破坏MPI网络的有序程度, 导致复合材料的结晶度下降, 但并不影响其多孔结构. 通过紫外漫反射光谱和光电流谱对Fe@MPI的光吸收能力和光生电 子/空穴对分离能力进行表征, 结果显示, MPI网络与 $\mathrm{Fe}^{3+}$ 配位后, 其光谱响应范围可拓宽至 $1250 \mathrm{~nm}$, 而其光电流响应强度 也较纯MPI提升了 3.5倍, 表明引入 $\mathrm{Fe}^{3+}$ 配位可有效促进光生电子/空穴对的分离. 基于其优异的光电性能, 我们以 $\mathrm{Fe} @ \mathrm{MPI}$ 为光催化剂, 在 $30^{\circ} \mathrm{C}$ 下实现了甲基丙烯酸甲酯的可见光诱导自由基聚合, 制备出分子量可达 $31.3 \times 10^{4} \mathrm{~g} \mathrm{~mol}^{-1}$ 的聚甲基丙 烯酸甲酯. 同时, 与 $\mathrm{MPI}$ 和 $\mathrm{FeCl}_{3}$ 相比, $\mathrm{Fe} @ \mathrm{MPI}$ 在相同条件下具有更高的催化效率, 与其光电性能相吻合. 最后, 催化剂回 收、循环实验表明, Fe@MPI易于回收, 且具有良好的结构和性能稳定性: 四次循环实验后, 其结构和光催化活性均可基本 保持不变.
\end{abstract}

关键词: 可见光; 光聚合; 聚酰亚胺基光催化剂; 铁离子配位

收稿日期: 2020-02-29. 接受日期: 2020-04-12. 出版日期: 2021-01-05.

*通讯联系人. 电话: (028)85405410; 传真: (028)85402465; 电子信箱: jianglong@scu.edu.cn

\#通讯联系人. 电话: (028)85405410; 传真: (028)85402465; 电子信箱: danyi@scu.edu.cn

基金来源：国家自然科学基金课题(51573109); 高分子材料工程国家重点实验室(四川大学)自主课题(sklpme 2016-3-02, 2019-2-08); 中央高校基本科研业务费专项资金.

本文的电子版全文由Elsevier出版社在ScienceDirect上出版(http://www.sciencedirect.com/science/journal/18722067). 